\title{
Multifunctions of Pleurotus sajor-caju (Fr.) Singer: A highly nutritious food and a source for bioactive compounds
}

\author{
Tiane C. Finimundy ${ }^{\mathrm{a}, \mathrm{b}}$, Lillian Barros ${ }^{\mathrm{a}}$, Ricardo C. Calhelha ${ }^{\mathrm{a}}$, Maria José Alves ${ }^{\mathrm{a}, \mathrm{c}}$, \\ Miguel A. Prieto $^{\mathrm{a}, \mathrm{d}}$, Rui M.V. Abreu ${ }^{\mathrm{a}}$, Aldo J.P. Dillon ${ }^{\mathrm{b}}$, João A.P. Henriques ${ }^{\mathrm{b}}$, \\ Mariana Roesch-Ely ${ }^{\mathrm{b}}$, Isabel C.F.R. Ferreira ${ }^{\mathrm{a}, *}$ \\ a Centro de Investigação de Montanha (CIMO), ESA, Instituto Politécnico de Bragança, Campus de Santa Apolónia, 5300-253 Bragança, Portugal \\ b Instituto de Biotecnologia, Universidade de Caxias do Sul, Caxias do Sul, RS, Brazil \\ c Escola Superior de Saúde, Instituto Politécnico de Bragança, Av. D. Afonso V, 5300-121 Bragança, Portugal \\ ${ }^{\mathrm{d}}$ Nutrition and Bromatology Group, Faculty of Food Science and Technology, University of Vigo, Ourense Campus, E32004 Ourense, Spain
}

\section{A R T I C L E I N F O}

\section{Keywords:}

Pleurotus sajor-caju

Nutrients

Extraction optimization

Phenolic acids

Bioactive properties

COX-2

\begin{abstract}
A B S T R A C T
A study with Pleurotus sajor-caju was conducted to: evaluate the nutritional and chemical composition of the fruiting bodies; optimize the preparation of bioactive phenolic extracts; and characterize the optimized extract in terms of bioactive compounds and properties. P. sajor-caju revealed an equilibrated nutritional composition with the presence of hydrophilic (sugars and organic acids) and lipophilic (tocopherols and PUFA) compounds. $p$ Hydroxybenzoic, $p$-coumaric and cinnamic acids were identified in the extract obtained with ethanol (30 g/ ratio) at $55{ }^{\circ} \mathrm{C}$ for $85 \mathrm{~min}$. This extract showed antioxidant properties (mainly reducing power and lipid peroxidation inhibition), antibacterial activity against MRSA and MSSA and cytotoxicity against NCI-H460, MCF-7 and HeLa. Furthermore, as the extract showed capacity to inhibit NO production in Raw 264.7 macrophages, molecular docking studies were performed to provide insights into the anti-inflammatory mechanism of action, through COX-2 inhibition by the phenolic acids identified.
\end{abstract}

\section{Introduction}

Pleurotus sajor-caju (Fr.) Singer (Pleurotaceae, Basidiomycetes higher) is a tasty mushroom with high nutritional value, therapeutic properties and diverse environmental and biotechnological applications (Han, Ahmad, \& Ishak, 2016). It is nutritionally rich in protein, fibre, minerals and vitamins, and is low in calories with very low lipid or starch contents. This mushroom has also been widely used in traditional medicine because of its various bioactive properties, including antiviral (Teplyakova \& Kosogova, 2016), antibacterial (Heleno et al., 2015), antifungal (Alves et al., 2013), antiparasitic (Ademola \& Odeniran, 2017), antitumor (Ferreira et al., 2015), antioxidant (Ferreira, Barros, \& Abreu, 2009), antihypertensive (through active ingredients that affect the renin-angiotensin system) (Chang \& Wasser, 2012), antidiabetic, preventing hyperglycemia and insulin resistance (Kanagasabapathy et al., 2012) and anti-inflammatory (Taofiq et al., 2016).

P. sajor-caju has been receiving great interest in research because of its biologically active compounds, such as polysaccharides (e.g. pleurane, a $\beta$-glucan), proteoglycans, phenolic acids, terpenes, proteins, and sterols, becoming a source of nutraceuticals (Duru \& Cayan, 2015). Phenolic compounds constitute one of the several categories with proven antioxidant effects, scavenging free radicals present in the body. The most abundant phenolic compounds reported in edible mushrooms belongs to the phenolic acids family, such as $p$-coumaric, $p$-hydroxybenzoic and protocatechuic acids (Barros, Duenas, Ferreira, Baptista, \& Santos-Buelga, 2009).

The extraction of bioactive compounds depend on the type of solvent, time and temperature used, as well as on the complexity of molecules, and should be optimized to obtain a higher overall efficiency of the target components (Heleno et al., 2016). According to Vongsak et al. (2013), heat assisted extraction (HAE) is the most used method for the extraction of phenolic compounds, which is simpler, more convenient and less costly in terms of instrumentation. However and as previously mentioned, it should be optimized to maximize the extraction of the bioactive compounds, monitoring the extraction yield by applying the Response Surface Methodology (RSM), where the effects of extremely important variables, such as time, temperature and solvent, are considered. The optimized bioactive extracts can be incorporated into supplements, nutraceuticals or functional foods (Milić, Rajković,

\footnotetext{
* Corresponding author

E-mail address: iferreira@ipb.pt (I.C.F.R. Ferreira).
} 
Stamenković, \& Veljković, 2013). Therefore, the aim of the present work was to highlight the diverse functional properties of fresh $P$. sajorcaju, taking advantage of its high nutritional value, as well as used to extract high valuable bioactive compounds for supplements' formulations.

\section{Material and methods}

\subsection{Mushroom sample}

Fresh samples of Pleurotus sajor-caju (Fr.) Singer (OS-2001) were purchased from a local producer in the South of Brazil. The botanical identification was confirmed by Ronaldo Adolfo Wasum, Professor of the University of Caxias do Sul. The fruiting bodies were dried at $30{ }^{\circ} \mathrm{C}$ in an oven, reduced to a fine dried powder ( $\sim 20$ mesh), mixed to obtain homogenous samples and stored in a desiccator, protected from light, until further analysis.

\subsection{Standards and reagents}

HPLC grade acetonitrile (99.9\%) was purchased from Fisher Scientific (Lisbon, Portugal). HPLC grade methanol was obtained from Lab-Scan (Lisbon, Portugal). Trolox (6-hydroxy-2,5,7,8-tetramethylchroman-2-carboxylic acid), phenolic acid standards (gallic, p-hydroxybenzoic, p-coumaric, protocatechuic and cinnamic acids), fatty acid methyl ester (FAME) reference standard mixture 37 (standard 47885-U), sugars ( $\mathrm{D}(-)$-fructose, $\mathrm{D}$ (-)-mannitol, $\mathrm{D}(+)$-raffinose pentahydrate, and $\mathrm{D}(+)$-trehalose), sulforhodamine $\mathrm{B}$, trypan blue, trichloroacetic acid (TCA), tris lipopolysaccharide (LPS) and dexamethasone were purchased from Sigma (St. Louis, MO, USA). 2,2-Diphenyl-1-picrylhydrazyl (DPPH) was obtained from Alfa Aesar (Ward Hill, MA, USA). Dulbecco's modified Eagle's medium (HyClone), Hank's balanced salt solution (HBSS) and all the additional culture media components were purchased from Gibco Invitrogen Life Technologies (Paisley, UK). RAW264.7 cells were acquired from ECACC ("European Collection of Animal Cell Culture") (Salisburg, UK), Griess reagent system kit was purchased from Promega (Madison, WI, USA).

The culture media Muller Hinton broth (MHB) and Tryptic Soy Broth (TSB) were obtained from Biomerieux (Marcy l'Etoile, France). Blood agar with 7\% sheep blood and Mac Conkey agar plates were purchased from bioMérieux (Marcy l'Etoile, France). The dye $p$-iodonitrotetrazolium chloride (INT) was also purchased from Sigma-Aldrich (St. Louis, MO, USA) and was used as microbial growth indicator. All other chemicals and solvents were of analytical grade and purchased from common sources. Water was treated in a Milli-Q water purification system (TGI PureWater Systems, Greenville, SC, USA).

\subsection{Analysis of the nutritional composition}

\subsubsection{Nutritional value}

Samples were analyzed for macronutrient composition (protein, carbohydrates, fat, moisture and ash) using AOAC procedures (AOAC, 2016). Crude protein content $(\mathrm{N} \times 4.38)$ was estimated by the macroKjeldahl method. Crude fat was determined using a Soxhlet apparatus by extracting a known weight of sample with petroleum ether. The ash content was determined by incineration at $600 \pm 15^{\circ} \mathrm{C}$. For moisture the sample was held in the oven to constant weight. Total carbohydrates were calculated by difference and total energy was calculated according to the following equation: Energy (kcal) $=4 \times(\mathrm{g}$ protein $+\mathrm{g}$ carbohydrates $)+9 \times(\mathrm{g}$ fat $)$.

\subsubsection{Free sugars}

Sugars were analyzed by high performance liquid chromatography coupled to a refractive index detector (HPLC-RI, Knauer, Smartline system 1000; Berlin, Germany), using a previously described procedure (Heleno et al., 2015). The chromatographic separation was achieved with a Eurospher 100-5 $\mathrm{NH}_{2}$ column $(4.6 \times 250 \mathrm{~mm}, 5 \mu \mathrm{m}$, Knauer,
Berlin, Germany) operating at $30{ }^{\circ} \mathrm{C}(7971 \mathrm{R}$ Grace oven). The mobile phase was acetonitrile/deionized water, 70:30 $(v / v)$ at a flow rate of 1 $\mathrm{ml} / \mathrm{min}$. Quantification and identification was based on the RI signal response of each standard, using raffinose as the internal standard (IS), and the results were expressed in $\mathrm{g}$ per $100 \mathrm{~g}$ of dry weight (dw).

\subsubsection{Organic acids}

Organic acids were determined by ultra-fast liquid chromatography coupled to a photo diode array detector (UFLC-DAD), following a previously described methodology (Heleno et al., 2015). Separation was achieved on a SphereClone reverse phase $\mathrm{C}_{18}$ column $(4.6 \times 250 \mathrm{~mm}$, $5 \mu \mathrm{m}$, Phenomenex, Torrance, CA, USA) thermostatted at $35^{\circ} \mathrm{C}$. The elution was performed with sulphuric acid $(3.6 \mathrm{mM})$ using a flow rate of $0.8 \mathrm{ml} / \mathrm{min}$. The identification was performed by comparing relative retention times and UV spectra with commercial standards. Quantification was accessed by area comparison of the peaks recorded at $215 \mathrm{~nm}$ with calibration curves obtained from commercial standards and results were expressed in $\mathrm{g}$ per $100 \mathrm{~g} \mathrm{dw}$.

\subsubsection{Fatty acids}

Fatty acids (obtained after Soxhlet extraction) were determined by gas chromatography with flame ionization detection (GC-FID)/capillary column, following a methodology previously described by Heleno et al. (2015). Separation was achieved in a Macherey-Nagel column $(50 \%$ cyanopropyl-methyl-50\% phenylmethylpolysiloxane, $30 \mathrm{~m} \times 0.32 \mathrm{~mm}$ i.d. $\times 0.25 \mu \mathrm{m} \mathrm{d}_{\mathrm{f}}$, Düren, Germany). The oven temperature program was as follows: the initial temperature of the column was $50{ }^{\circ} \mathrm{C}$, held for $2 \mathrm{~min}$, then a $30{ }^{\circ} \mathrm{C} / \mathrm{min}$ ramp to $125^{\circ} \mathrm{C}, 5^{\circ} \mathrm{C} / \mathrm{min}$ ramp to $160^{\circ} \mathrm{C}$, $20{ }^{\circ} \mathrm{C} / \mathrm{min}$ ramp to $180^{\circ} \mathrm{C}, 3{ }^{\circ} \mathrm{C} / \mathrm{min}$ ramp to $200{ }^{\circ} \mathrm{C}, 20^{\circ} \mathrm{C} / \mathrm{min}$ ramp to $220^{\circ} \mathrm{C}$ and held for $15 \mathrm{~min}$. The carrier gas (hydrogen) flow-rate was $4.0 \mathrm{ml} / \mathrm{min}(0.61 \mathrm{bar})$, measured at $50^{\circ} \mathrm{C}$. Split injection (1:40) was carried out at $250^{\circ} \mathrm{C}$. Fatty acid identification was made by comparing the relative retention times of FAME peaks from samples with standards. Fatty acids were processed using Clarity 4.0.1.7 Software (DataApex, Podohradska, Czech Republic), identification was performed by comparing the relative retention times from samples with standards and results were expressed in relative percentage (\%) of each fatty acid.

\subsubsection{Tocopherols}

Tocopherols were determined using a HPLC system (Smartline, Knauer, Germany), coupled to a fluorescence detector (FP-2020; Jasco, Japan) programmed for excitation at $290 \mathrm{~nm}$ and emission at $330 \mathrm{~nm}$, following a procedure previously described (Heleno et al., 2015). The chromatographic separation was achieved with a Polyamide II $(4.6 \times 250 \mathrm{~mm}, 5 \mu \mathrm{m}$, YMC Waters, Lisbon, Portugal) normal-phase column, operating at $30{ }^{\circ} \mathrm{C}$. The mobile phase used was a mixture of $n$ hexane and ethyl acetate $(70: 30, v / v)$ at a flow rate of $1 \mathrm{ml} / \mathrm{min}$. Data was processed using Clarity 2.4 Software (DataApex). Compounds were identified by chromatographic comparisons with commercial standards and quantification was based on the fluorescence signal response, using an internal standard method. Tocopherols content in mushrooms were expressed in $\mu \mathrm{g}$ per $100 \mathrm{~g} \mathrm{dw}$.

\subsection{Solid-liquid extraction of the P. sajor-caju samples. Heat assisted extraction (HAE)}

HAE is the conventional solid-liquid extraction method for researcher and industries to obtain compounds from plant matrices by stirring the sample in a solvent for a certain time and at a specific temperature (Heleno et al., 2016). The solid-liquid heat assisted extractions were performed by placing the dry powdered samples (600 mg) in an extraction vial with $20 \mathrm{ml}$ of solvent at a fixed solid/ liquid ratio $(30 \mathrm{~g} / \mathrm{l})$ and placed in a thermostatic water bath under continuous electro-magnetic stirring (500 rpm, CIMAREC Magnetic Stirrer) at each of the given $t, T$ and $S$ conditions defined by the RSM design (Table A1). 

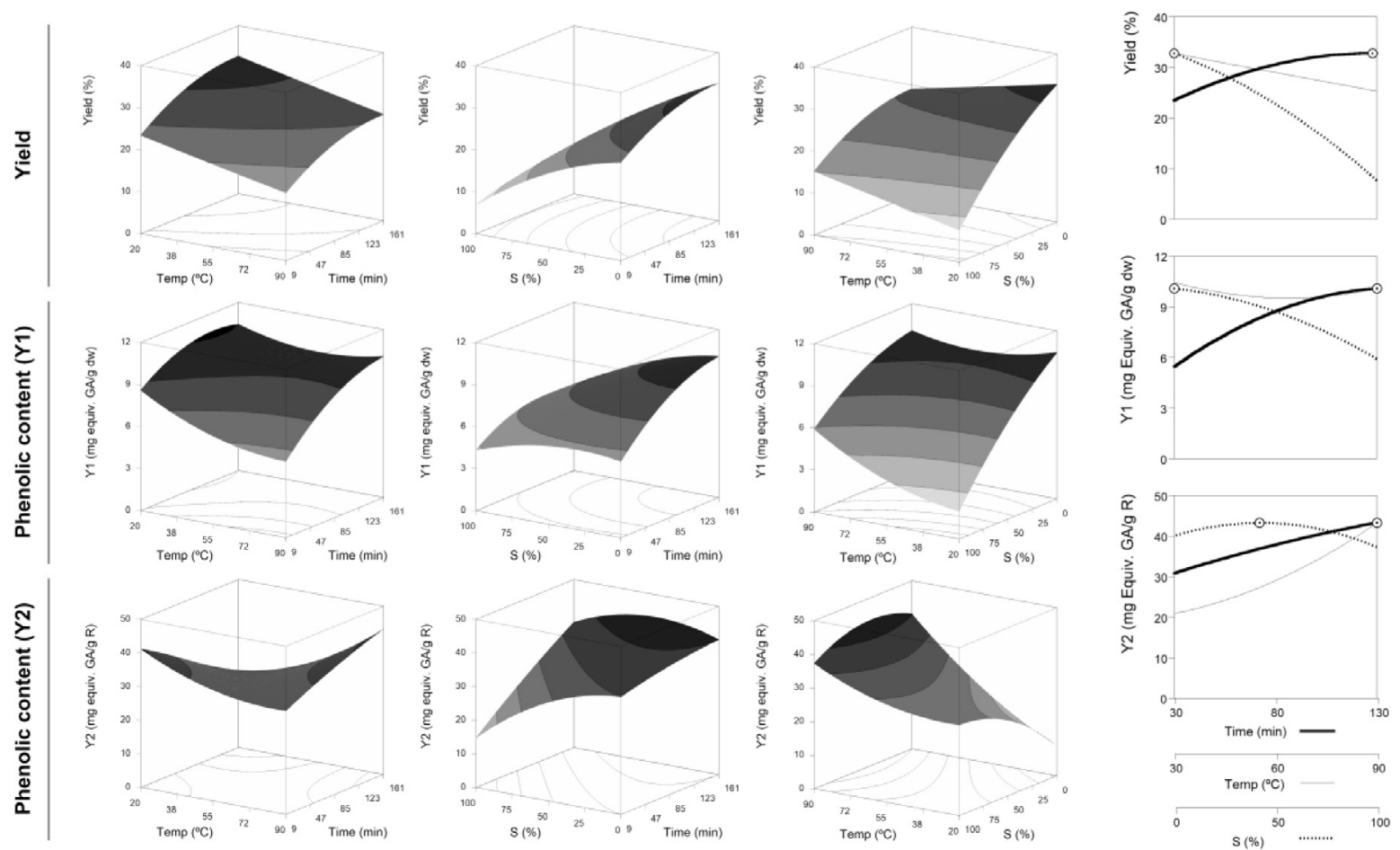

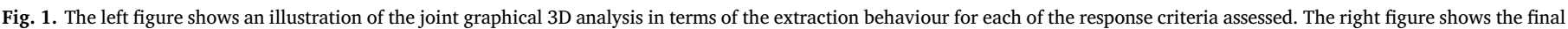

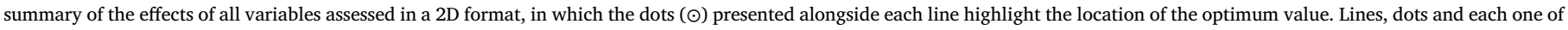
the net surfaces are generated by the theoretical second order polynomial models of Eqs. (2), (3) and (4).

\subsection{Optimization of the conditions to extract bioactive phenolics}

\subsubsection{Experimental design}

Variables and ranges were selected by preliminary analysis. Through the analysis of these experimental results (data not shown), time (t, from 10 to $160 \mathrm{~min}$ ), temperature ( $T$, from 20.0 to $90.0{ }^{\circ} \mathrm{C}$ ) and water-ethanol solvent proportions ( $S$, from 0 to $100 \%$ ) were chosen as the relevant variables and ranges for the RSM design. The combined variables effect on the HAE were studied using a circumscribed central composite design (CCCD) with five levels for each one (Table A1).

\subsubsection{Responses criteria used to evaluate the extraction process}

After the extraction at each given condition, the mixture was filtered (Whatman $\mathrm{n}^{\circ} 4$ paper) and centrifuged ( $4800 \mathrm{~g}$ for $10 \mathrm{~min}$ ). The pellet was discarded and the supernatant was collected and divided in two parts to analyze separately the main responses for the optimization procedure:

- One part was used to quantify the yield of residual material extracted (R) expressed as percentage (\%) of the P. sajor-caju dry material used;

- The second part of the supernatant was evaporated, lyophilized, and then employed to quantify spectrophotometrically (UV-160A; Shimadzu Corporation, Kyoto, Japan) the phenolics. The phenolic content $(\mathrm{Ph})$ was estimated by a colourimetric procedure. Briefly, a $P$. sajor-caju extract solution $(1 \mathrm{ml})$ in the concentration of $30 \mathrm{~g} / 1$ was mixed with Folin-Ciocalteu reagent $(5 \mathrm{ml}$, previously diluted with water $1: 10, \mathrm{v} / \mathrm{v})$ and sodium carbonate $\mathrm{Na}_{2} \mathrm{CO}_{3}(75 \mathrm{~g} / \mathrm{l}, 4 \mathrm{ml})$ in triplicate. The tubes were vortex for $15 \mathrm{~s}$ and allowed to stand for $30 \mathrm{~min}$ at $40{ }^{\circ} \mathrm{C}$ for colour development. Absorbance was then measured at $765 \mathrm{~nm}$. Gallic acid $(9.4-150 \mu \mathrm{g} / \mathrm{ml})$ was used to obtain the standard curve. Results were expressed as $\mathrm{mg}$ of gallic acid equivalents per $\mathrm{g}$ of $P$. sajor-caju dw (mg GAE/g dw).

Therefore, three responses are used as criterion for optimization purposes: 1) the R yield extracted (in\% and described as yield); 2) the phenolic content in the $P$. sajor-caju dry material (in $\mathrm{mg} \mathrm{GAE} / \mathrm{g} \mathrm{dw}$ and described as $P h-Y_{1}$ ); and 3) an additional response that depends on the other two responses can be computed for the phenolic content in the $\mathrm{R}$ (in mg GAE/g R and described as $P h-Y_{2}$ ).

\subsubsection{Mathematical model development and statistical assessment}

All analysis were performed in Microsoft Excel. Models were fitted by the 'Solver' macro by minimization of the sum of quadratic differences between observed and model-predicted values using the following second-order polynomial equation:

$Y=b_{0}+\sum_{i=1}^{n} b_{i} X_{i}+\sum_{\substack{i=1 \\ j>i}}^{n-1} \sum_{j=2}^{n} b_{i j} X_{i} X_{j}+\sum_{i=1}^{n} b_{i i} X_{i}^{2}$

where $Y$ is the dependent variable (response variable) to be modelled, $X_{i}$ and $X_{j}$ define the independent variables, $b_{o}$ is the constant coefficient, $b_{i}$ is the coefficient of linear effect, $b_{i j}$ is the coefficient of interaction effect, $b_{i i}$ the coefficients of quadratic effect and $n$ is the number of variables. The parametric confidence intervals were determined via 'SolverAid' macro (Prieto, Curran, Gowen, \& Vázquez, 2015) and final model reliability was confirmed by applying the following criteria: a) the Fisher $F$-test ( $\alpha=0.05$ ) to test model consistency; b) assessment of the parameter and model prediction uncertainties by the 'SolverStat' macro (Prieto, Murado, \& Vázquez, 2014); and c) R2 coefficient to explain the proportion variability of the dependent variable obtained by the model.

2.5.4. Optimization procedure of the variables to maximize the responses

The second-order polynomial model produced for each of the responses was used for variables optimization and response maximization by a simplex method using the 'Solver' macro in Microsoft Excel (Albuquerque et al., 2017). Limitations were made to the variable coded values to avoid unnatural conditions (i.e., times lower than 0 ). 
a)

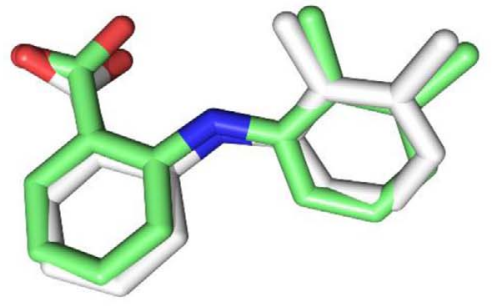

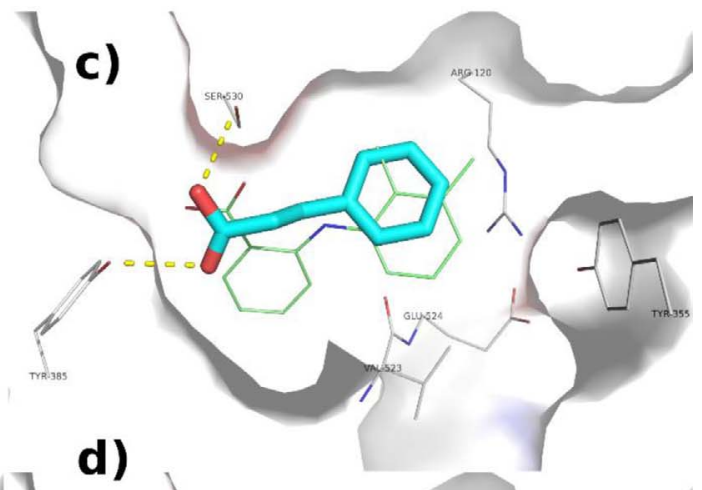

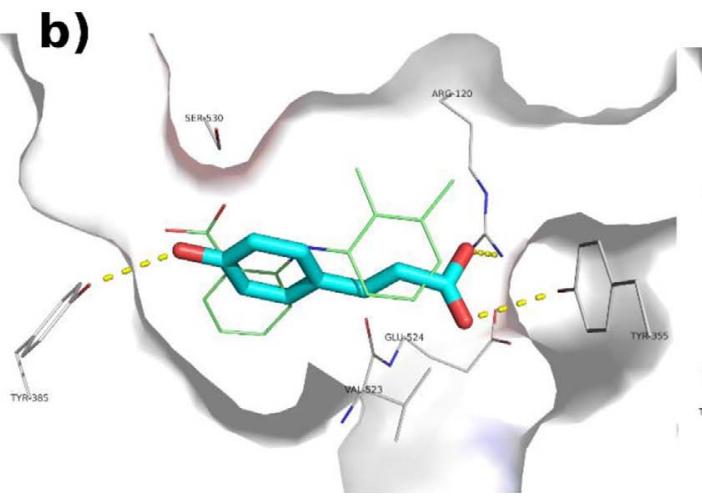

d)

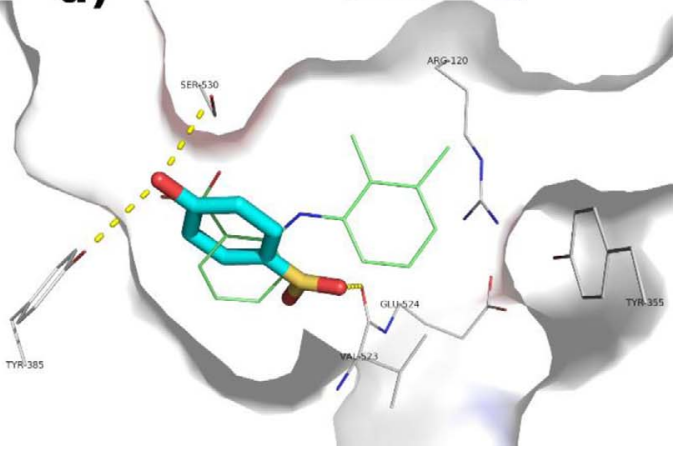

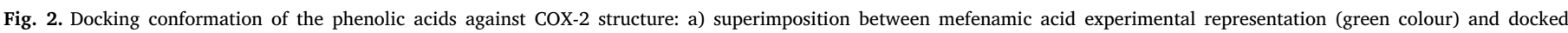

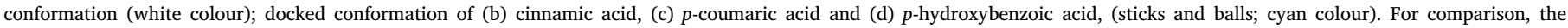

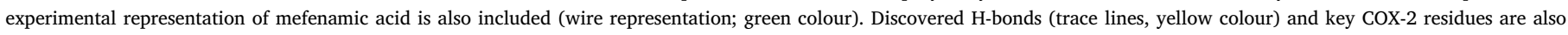
presented. (For interpretation of the references to colour in this figure legend, the reader is referred to the web version of this article.)

\subsection{Chemical characterization of the optimized extract}

The optimized conditions of the extraction procedure that maximize the response criteria used were dissolved in $100 \%$ ethanol $(20 \mathrm{mg} / \mathrm{ml})$, filtered through a $0.22 \mu \mathrm{m}$ nylon syringe filter and further analyzed by HPLC-DADESI/MSn on a Dionex Ultimate 3000 UPLC (ThermoScientific, San Jose, CA, USA) system following a procedure previously reported by Svobodova et al. (2017). The equipment consisted of a diode array detector coupled to an electrospray ionization mass detector, a quaternary pump, an auto-sampler (kept at $5{ }^{\circ} \mathrm{C}$ ), a degasser and an automated thermostated column section (kept at $\left.35^{\circ} \mathrm{C}\right)$. Waters Spherisorb S3 ODS-2 $\mathrm{C}_{18}(3 \mu \mathrm{m}, 4.6 \times 150 \mathrm{~mm}$, Waters, Milford, MA, USA) column provided chromatographic separations. The solvents used were (A) $0.1 \%$ formic acid in water and (B) acetonitrile. The gradient elution applied was: $15 \% \mathrm{~B}(0-5 \mathrm{~min}), 15 \% \mathrm{~B}$ to $20 \% \mathrm{~B}$ (5-10 $\mathrm{min}$ ), $20-25 \%$ B (10-20 $\mathrm{min}$ ), $25-35 \%$ B (20-30 $\mathrm{min}$ ), 35-50\% B (30-40 $\mathrm{min}$ ), the column was then re-equilibrated, using a flow rate of $0.5 \mathrm{ml} / \mathrm{min}$. Data were collected simultaneously with DAD (280 and $370 \mathrm{~nm}$ ) and in negative mode detection on a Linear Ion Trap LTQ XL mass spectrometer (ThermoScientific, San Jose, CA, USA). Sheath gas (nitrogen) was kept on 50 psi. Other parameters settings: source temperature $325^{\circ} \mathrm{C}$, spray voltage $5 \mathrm{kV}$, capillary voltage $-20 \mathrm{~V}$, tube lens offset $-66 \mathrm{~V}$, collision energy 35 arbitrary units. The full scan captured the mass between $\mathrm{m} /$ z 100 and 1500. Xcalibur ${ }^{\circledast}$ data system (ThermoScientific, San Jose, CA, USA) was operating the data acquisition. For identification, retention times, UV-VIS and mass spectra were compared with available standards and data from literature were used to tentatively identify the remaining compounds. Calibration curves of available phenolic standards were constructed based on the UV signal to perform quantitative analysis. The results were expressed as $\mu \mathrm{g} / \mathrm{g}$ of extract.

\subsection{Bioactive properties of the optimized extract}

The extract obtained in the optimized conditions of the extraction procedure that maximize the response criteria used were used to evaluate the bioactive properties

\subsubsection{General preparation of stock solutions for bioactivity analysis}

The optimized extract was re-dissolved in ethanol/water (80:20, v/ v) and water at 20 and $100 \mathrm{mg} / \mathrm{ml}$ for antioxidant and antimicrobial assays, respectively. For cytotoxicity and anti-inflammatory activity evaluation, the extract was re-dissolved in water, with a final solution of $8 \mathrm{mg} / \mathrm{ml}$. The stock solutions were diluted to different concentrations to be submitted to the following assays.

\subsubsection{Antioxidant activity}

The antioxidant activity was evaluated by DPPH radical-scavenging activity, reducing power, inhibition of $\beta$-carotene bleaching in the presence of linoleic acid radicals and inhibition of lipid peroxidation using TBARS in brain homogenates. The extract concentrations providing $50 \%$ of antioxidant activity or 0.5 of absorbance $\left(\mathrm{EC}_{50}\right)$ were calculated from the graphs of antioxidant activity percentages (DPPH, $\beta$-carotene bleaching and TBARS assays) or absorbance at $690 \mathrm{~nm}$ (reducing power assay), against extract concentration (Svobodova et al., 2017). Trolox was used as positive control.

\subsubsection{Cytotoxic activity in tumour and non-tumour cells}

The cytotoxicity was determined using four human tumour cell lines, HeLa (cervical carcinoma), HepG2 (hepatocellular carcinoma), MCF-7 (breast adenocarcinoma) and NCI-H460 (non-small cell lung cancer). The cell growth inhibition was measured using sulforhodamine $\mathrm{B}$ (SRB) assay, where the amount of pigmented cells is directly proportional to the total protein content and, therefore, to the number of bound cells (Svobodova et al., 2017). For hepatotoxicity evaluation, a freshly harvested porcine liver, obtained from a local slaughter house, was used in order to obtain the cell culture, designated as PLP2. The results were expressed in $\mathrm{GI}_{50}$ values; sample concentration that inhibited $50 \%$ of the net cell growth and ellipticine was used as positive control.

\subsubsection{Antibacterial activity}

Bacteria strains were clinical isolates obtained from patients hospitalized 
Table 1

Nutritional composition of $P$. sajor caju fruiting bodies expressed in dry weight basis (mean $\pm \mathrm{SD}$ )

\begin{tabular}{ll}
\hline Nutritional value & \\
Moisture $(\mathrm{g} / 100 \mathrm{~g})$ & $91.06 \pm 0.09$ \\
Ash $(\mathrm{g} / 100 \mathrm{~g})$ & $5.4 \pm 0.5$ \\
Proteins $(\mathrm{g} / 100 \mathrm{~g})$ & $17.29 \pm 0.06$ \\
Fat $(\mathrm{g} / 100 \mathrm{~g})$ & $1.16 \pm 0.03$ \\
Carbohydrates $(\mathrm{g} / 100 \mathrm{~g})$ & $76.2 \pm 0.4$ \\
Energy $(\mathrm{kcal} / 100 \mathrm{~g})$ & $384 \pm 2$ \\
Sugars Content $(\mathrm{g} / 100 \mathrm{~g})$ & \\
Mannitol & $3.2 \pm 0.2$ \\
Trehalose & $10.1 \pm 0.5$ \\
Total sugars & $13.3 \pm 0.7$ \\
Organic acids Content $(\mathrm{g} / 100)$ & \\
Oxalic acid & $1.18 \pm 0.05$ \\
Malic acid & $1.80 \pm 0.08$ \\
Fumaric acid & $0.37 \pm 0.03$ \\
Total organic acids & $3.4 \pm 0.2$ \\
Tocopherols $(\mu \mathrm{g} / 100 \mathrm{~g})$ & \\
$\alpha$-Tocopherol & \\
$\beta$-Tocopherol & $3.4 \pm 0.8$ \\
$\delta$-Tocopherol & $682 \pm 6$ \\
Total tocopherols & $19 \pm 3$ \\
\end{tabular}

\begin{tabular}{ll} 
Fatty acids (\%) & \\
C6:0 & $0.24 \pm 0.04$ \\
C8:0 0 & $0.080 \pm 0.001$ \\
C10:0 & $0.042 \pm 0.004$ \\
C12:0 & $0.115 \pm 0.002$ \\
C14:0 & $0.45 \pm 0.04$ \\
C14:1 & $0.241 \pm 0.007$ \\
C15:0 & $2.48 \pm 0.03$ \\
C16:0 & $17.17 \pm 0.04$ \\
C17:0 & $0.477 \pm 0.007$ \\
C18:0 & $3.79 \pm 0.07$ \\
C18:1n9 & $16.11 \pm 0.03$ \\
C18:2n6 & $53.7 \pm 0.2$ \\
C18:3n6 $18: 3 n 3$ & $0.101 \pm 0.007$ \\
C20:1 & $0.084 \pm 0.002$ \\
C20:2 & $0.49 \pm 0.02$ \\
C20:3n3+C21:0 & $0.42 \pm 0.04$ \\
C20:5n3 & $0.276 \pm 0.004$ \\
C22:0 & $0.10 \pm 0.01$ \\
C22:1n9 & $1.39 \pm 0.09$ \\
C23:0 & $0.163 \pm 0.006$ \\
C24:0 & $0.32 \pm 0.01$ \\
C24:1 & $0.73 \pm 0.06$ \\
SFA & $1.05 \pm 0.01$ \\
MUFA & $27.3 \pm 0.2$ \\
PUFA & $18.05 \pm 0.01$ \\
& $54.7 \pm 0.2$ \\
\hline
\end{tabular}

Caproic acid (C6:0); Caprylic acid (C8:0); Capric acid (C10:0); Lauric acid (C12:0); Myristic acid (C14:0); myristoleic acid (C14:1); Pentadecanoic acid (C15:0); Palmitic acid (C16:0); Heptadecanoic acid (C17:0); Stearic acid (C18:0); Oleic acid (C18:1n9); Linoleic acid (C18:2n6); $\gamma$-Linolenic acid (C18:3n6); $\alpha$-Linolenic acid (C18:3n3); Eicosenoic acid (C20:1); Eicosadienoic acid (C20:2); Eicosatrienoic acid (C20:3n3); Eicosapentaenoic acid (C20:5n3); Behenic acid (C22:0); Docosenoic acid (C22:1n9); Tricosanoic acid (C23:0); Lignoceric acid (C24:0); Tetracosenoic acid (C24:1). SFA-Saturated fatty acids; MUFAMonounsaturated fatty acids; PUFA-Polyunsaturated fatty acids.

in various departments at the Hospital Center of Trás-os-Montes and Alto Douro (Vila Real, Portugal). Four Gram-positive bacteria (Enterococcus faecalis isolated from urine, Listeria monocytogenes isolated from cerebrospinal fluid, MSSA: methicillin-sensitive Staphylococcus aureus isolated from wound exudate and MRSA: methicillin-resistant Staphylococcus aureus, isolated from expectoration), and six Gram-negative bacteria (Pseudomonas aeruginosa isolated from expectoration, Escherichia coli, Escherichia coli spectrum extended producer of $\beta$-lactamases (ESBL), Klebsiella pneumoniae, Klebsiella pneumoniae ESBL and Morganella morganii, all isolated from urine). All the tested bacteria were placed to grow in the appropriate fresh medium, $24 \mathrm{~h}$, and kept in the oven at $37^{\circ} \mathrm{C}$ before analysis in order to maintain the exponential growth phase (Svobodova et al., 2017).
The determination of the minimal inhibitory concentration (MIC) was performed on a 96-well microplate by the method $p$-iodonitrotetrazolium chloride (INT) colourimetric assay (Svobodova et al., 2017). Initially, $40 \mu \mathrm{l}$ of the extract solution was added to $150 \mu \mathrm{l}$ of medium TSB or MHB, according to the bacteria requirements. Afterwards, $10 \mu \mathrm{l}$ of inoculum $\left(1.5 \times 10^{8} \mathrm{CFU} / \mathrm{ml}\right)$ was added to all 96-wells thus achieving a concentration range of $20-0.156 \mathrm{mg} / \mathrm{ml}$. The plates were then incubated at $37^{\circ} \mathrm{C}$, for $24 \mathrm{~h}$, in an oven (Jouan, Berlin, Germany). The MIC of the samples was determined after adding INT $(0.2 \mathrm{mg} / \mathrm{ml})$ and after incubation at $37{ }^{\circ} \mathrm{C}$ for $30 \mathrm{~min}$. Viable microorganisms reduced the yellow dye to a pink colour. MIC was defined as the lowest extract concentration that prevented this change, thus showing complete inhibition of bacterial growth.

Microorganism's identification and susceptibility tests were performed using the MicroScan panels (MicroScan ${ }^{\circledast}$; Siemens Medical Solutions Diagnostics, West Sacramento, CA, USA) by the microdilution method (Svobodova et al., 2017). The interpretation criteria were based on Interpretive Breakpoints as indicated in Clinical and Laboratory Standards Institute (CLSI, 2008) and in the European Committee on Antimicrobial Susceptibility Testing (EUCAST, 2013).

\subsubsection{Anti-inflammatory activity}

2.7.5.1. NO production inhibition. The LPS-induced NO production by Murine macrophage (RAW 264.7) cell lines was determined as nitrite concentration in the culture medium (Svobodova et al., 2017). Dexamethasone $(50 \mu \mathrm{M})$ was used as a positive control. The mouse macrophage-like cell line RAW 264.7 stimulated with LPS was used in the assay. Nitric oxide (NO) production was studied with Griess Reagent System kit. Results were expressed as $\mathrm{IC}_{50}$ values $(\mu \mathrm{g} / \mathrm{ml})$ equal to the sample concentration providing a $50 \%$ inhibition of NO production. Dexamethasone was used as positive control.

2.7.5.2. Molecular docking. The selected COX-2 crystal structure was obtained from the Protein Data Bank (PDB entry: 5KIR). The cocrystallized ligand, in this case mefenamic acid, was separated from the corresponding protein structure and used to perform the docking validation. All crystallized water molecules were removed from the structure. AutoDockTools1.5.2 (ADT) (Morris, Huey, \& Olson, 2008) was then used to assign polar hydrogens, add Gasteiger charges and save the protein structure in PDBQT file format. The docking grid was defined using ADT. The $\mathrm{X}, \mathrm{Y}, \mathrm{Z}$ center coordinates and $\mathrm{X}, \mathrm{Y}, \mathrm{Z}$ grid dimensions were selected and used for all docking simulations. The 2D structure of the three studied compounds ( $p$-hydroxybenzoic, $p$ coumaric and cinnamic acids), were drawn using ACD/ChemSketch Freeware 12.0 software. VegaZZ software was then used to perform 2D to 3D conversion and to save the structures in PDB file format. Finally, ADT was used to convert PDB to PDBQT file format. All docking simulations were performed using AutoDock Vina software (Trott \& Olson, 2010), using an exhaustiveness parameter of 16. Docking conformation analysis and image preparation was performed using PyMOL software (Delano, 2002). Autodock Vina was subsequently used to perform all docking simulations for each structure in the cocrystallized ligands, and with the necessary dimensions to encompass the ligand binding site. All figures with structure representations were produced using PyMOL.

\section{Results and discussion}

\subsection{Nutritional value of the fruiting bodies}

Nutritional composition and energetic contribution of Pleurotus sajor-caju (PSC) are shown in Table 1. The overall macronutrients balance is in accordance with literature (Obodai et al., 2014) reported a moisture value of $90 \mathrm{~g} / 100 \mathrm{~g}$, while described $89.58 \mathrm{~g} / 100 \mathrm{~g}$. The fat content found was also according to Goyal, Grewal, and Goyal (2006) (1.96 g/100 g). According to Gogavekar et al. (2014), the carbohydrates content mainly includes glucose, 
Table 2

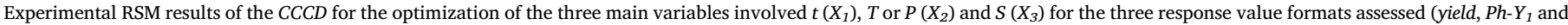

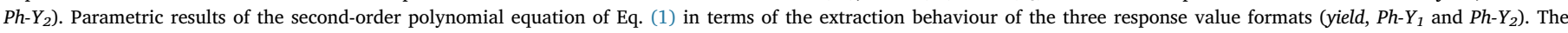

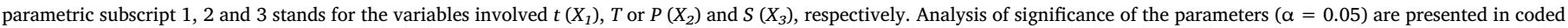
values.

\begin{tabular}{|c|c|c|c|c|c|}
\hline \multicolumn{3}{|c|}{ Variable coded values } & \multicolumn{3}{|c|}{ Experimental responses } \\
\hline$X_{1}$ & $X_{2}$ & $X_{3}$ & Yield & $P h-Y_{1}$ & $P h-Y_{2}$ \\
\hline-1 & -1 & -1 & 21.67 & 7.24 & 33.40 \\
\hline 1 & -1 & -1 & 53.83 & 8.56 & 15.90 \\
\hline-1 & 1 & -1 & 18.50 & 5.02 & 27.13 \\
\hline 1 & 1 & -1 & 22.83 & 8.03 & 35.16 \\
\hline-1 & -1 & 1 & 18.33 & 5.99 & 32.66 \\
\hline 1 & -1 & 1 & 19.67 & 6.94 & 35.28 \\
\hline-1 & 1 & 1 & 18.17 & 5.99 & 32.97 \\
\hline 1 & 1 & 1 & 21.73 & 7.21 & 33.20 \\
\hline-1.68 & 0 & 0 & 18.50 & 6.03 & 32.60 \\
\hline 1.68 & 0 & 0 & 20.83 & 6.33 & 30.40 \\
\hline 0 & -1.68 & 0 & 20.00 & 6.68 & 33.39 \\
\hline 0 & 1.68 & 0 & 24.33 & 9.08 & 37.30 \\
\hline 0 & 0 & -1.68 & 31.83 & 11.40 & 35.81 \\
\hline 0 & 0 & 1.68 & 7.33 & 2.56 & 34.87 \\
\hline 0 & 0 & 0 & 21.83 & 6.82 & 31.24 \\
\hline 0 & 0 & 0 & 22.83 & 6.83 & 29.89 \\
\hline 0 & 0 & 0 & 22.67 & 7.18 & 31.69 \\
\hline 0 & 0 & 0 & 24.17 & 7.46 & 30.85 \\
\hline 0 & 0 & 0 & 22.00 & 7.28 & 33.08 \\
\hline 0 & 0 & 0 & 22.00 & 7.49 & 34.05 \\
\hline \multicolumn{6}{|c|}{ Parametric responses } \\
\hline \multicolumn{2}{|l|}{ Fitting coefficients } & & Yield & $\mathrm{Ph}-\mathrm{Y}_{1}$ & $\mathrm{Ph}-\mathrm{Y}_{2}$ \\
\hline Intercept & $b_{o}$ & & $22.58 \pm 1.10$ & $7.17 \pm 0.64$ & $31.60 \pm 1.87$ \\
\hline \multirow[t]{3}{*}{ Linear effect } & \multirow{2}{*}{$b_{1}$} & & $1.45 \pm 0.26$ & $0.51 \pm 0.03$ & $-0.76 \pm 0.16$ \\
\hline & & & & & $1.30 \pm 0.26$ \\
\hline & $b_{3}$ & & $-4.00 \pm 0.86$ & $-1.42 \pm 0.03$ & $n s$ \\
\hline \multirow[t]{3}{*}{ Quadratic effect } & $b_{11}$ & & $-0.86 \pm 0.13$ & $-0.34 \pm 0.02$ & $n s$ \\
\hline & $b_{22}$ & & ns & $0.26 \pm 0.02$ & $1.11 \pm 0.11$ \\
\hline & $b_{33}$ & & $-0.89 \pm 0.23$ & $-0.25 \pm 0.02$ & $-1.56 \pm 0.11$ \\
\hline Interactive effect & $b_{12}$ & & $n s$ & $n s$ & $2.89 \pm 0.13$ \\
\hline & $b_{13}$ & & $-0.77 \pm 0.13$ & $n s$ & $1.54 \pm 0.17$ \\
\hline & $b_{23}$ & & $1.33 \pm 0.13$ & $0.38 \pm 0.06$ & $-1.85 \pm 0.19$ \\
\hline
\end{tabular}

trehalose, mannitol, glycogen and some other polysaccharides with recognized therapeutic effects. Gupta, Sharma, Saha, and Walia (2013), also described mannitol and trehalose as the major sugars in this mushroom species. Malic, oxalic and fumaric acids were the organic acids found in PSC, with the prevalence of the malic acid (Table 1). However, the profile of organic acids described by Obodai et al., 2014 was slightly different since the authors did not detect malic acid. Twenty-three fatty acids were quantified in PSC and the most abundant was linoleic acid (C18:2n6). A prevalence of PUFA over SFA was observed and the global percentages obtained are very similar to those described in other studies (Kayode et al., 2015; Obodai et al., 2014). Saturated fatty acids (SFA), monounsaturated (MUFA) and polyunsaturated (PUFA) are shown in Table 1. According to Khan and Tania (2012), many environmental factors affect the lipid content, that is naturally low in mushrooms. Nevertheless, they are sources of some essential fatty acids for the human body. PSC also contains tocopherols, mainly $\beta$-tocopherol; $\gamma$-tocopherol was not found, which is in agreement with the results described for other Pleurotus species (Yang, Lin, \& Mau, 2002). Tocopherols are natural antioxidants because they act as free peroxyl radical scavengers.

\subsection{Optimized conditions to extract bioactive phenolics}

Heat assisted extraction (HAE) is a conventional solid-liquid extraction method frequently used to obtain compounds from plant matrices. It is a simple technique with lower requirements in terms of equipment, but very often involves long time periods and high temperatures. The extraction of target compounds from matrices requires a specific consideration due to the intrinsic nature and stability of these target compounds (Heleno et al., 2016). Therefore, to maximize the response extraction of these compounds, it is essential to identify the response effects caused by the main variables involved using the minimum time, energy and solvent consumption and designing the most cost-effective and profitable extraction system. The RSM design allows optimizing all the variables simultaneously considering interactive reactions and to predict the most efficient conditions (Albuquerque et al., 2017).

3.2.1. Mathematical models derived from the RSM for a CCCD with three variables and statistical assessment

The results obtained by the statistical CCCD are shown in the first part of Table 2 for each one of the response criteria used. By fitting the second-order polynomial model of Eq. (1) to the obtained responses using nonlinear least-squares estimations, the parametric values are obtained and presented in Table 2. Therefore, the resulting models for each response format are as follows:

$Y_{\text {Yield }}=22.58+1.45 t-4.0 S-0.86 t^{2}-0.89 S^{2}-0.77 t S+1.33 T S$ 
Table 3

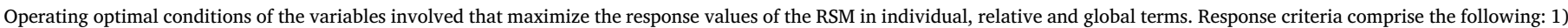
$\%$ yield of extraction of the residue (R); and 2) spectrophotometric quantification of total phenolic (Ph) in both response format values ( $P h-Y_{1}$ and $\left.P h-Y_{2}\right)$.

\begin{tabular}{|c|c|c|c|c|c|}
\hline \multirow[t]{2}{*}{ Criteria } & \multicolumn{3}{|c|}{ Optimal variable conditions } & \multirow[t]{2}{*}{ Optimum response } & \\
\hline & $\mathrm{X}_{1}: \mathrm{t}(\mathrm{min})$ & $\mathrm{X}_{2}: \mathrm{T}\left({ }^{\circ} \mathrm{C}\right)$ & $\mathrm{X}_{3}: \mathrm{S}(\%)$ & & \\
\hline \multicolumn{6}{|c|}{ A) Individual optimal variable conditions } \\
\hline Yield & 157.4 & 20.0 & 0.0 & 32.75 & $\%$ \\
\hline $\mathrm{Ph}-\mathrm{Y}_{1}$ & 160.7 & 90.0 & 0.0 & 10.08 & $\mathrm{mg} \mathrm{GAE} / \mathrm{g} \mathrm{dw}$ \\
\hline $\mathrm{Ph}-\mathrm{Y}_{2}$ & 160.7 & 90.0 & 42.1 & 43.30 & mg GAE/g R \\
\hline \multicolumn{6}{|c|}{ B) Relative optimal variable conditions using response analysis of $\mathrm{pH}$} \\
\hline Yield & 157.4 & 20.0 & 0.0 & 32.75 & $\%$ \\
\hline $\mathrm{Ph}-\mathrm{Y}_{1}$ & 160.7 & 90.0 & 15.6 & 9.8 & $\mathrm{mg} \mathrm{GAE} / \mathrm{g} \mathrm{dw}$ \\
\hline $\mathrm{Ph}-\mathrm{Y}_{2}$ & & & & 42.0 & mg GAE/g R \\
\hline \multicolumn{6}{|c|}{ C) Global optimal variable conditions } \\
\hline Yield & 140.6 & 90.0 & 72.4 & 20.61 & $\%$ \\
\hline $\mathrm{Ph}-\mathrm{Y}_{1}$ & & & & 7.7 & mg GAE/g dw \\
\hline $\mathrm{Ph}-\mathrm{Y}_{2}$ & & & & 39.7 & mg GAE/g R \\
\hline
\end{tabular}

$Y_{P h-Y_{1}}=7.17+0.51 t-1.42 S-0.34 t^{2}+0.26 T^{2}-0.25 S^{2}-0.38 T S$

$Y_{P h-Y_{2}}=31.6-0.76 t+1.3 T+1.11 T^{2}-1.56 S^{2}+2.89 t T+1.54 t S-1.85 T S$

Those coefficients, which showed confidence interval values $(\alpha=0.05)$ higher than the parameter value, were consider as nonsignificant (ns) and were not used for the model development.

Overall, the response patterns for the three response criteria formats (yield, $P h-Y_{1}$ and $P h-Y_{2}$ ) show a relatively high complexity of the possible sceneries. For each response criteria, the linear and quadratic effects are found to play an important and significant role, meanwhile regarding the interactive effects, only the $P h-Y_{2}$ response showed significant effects for all the possible combinations.

Fig. 1, part A, shows the extraction results for the three response criteria formats used. The 3D figures are organized in three rows, each row contains each one of the responses obtained. Each row shows the 3D surface plots for the three possible variable combinations produced by the described Eqs. (2), (3) and (4). The binary action between variables is presented when the excluded variable is positioned at the center of the experimental domain (see Table A1, Supplementary material). In almost all combinatory 3D responses of Fig. 1, the responses increases to an optimum value and then decreases as a function of each of the assessed independent variables. Therefore, in almost all combinations, an absolute optimum can be found at one single point along with the response, allowing computing the conditions that lead to the absolute maximum.

In statistical terms, the tests used to assess the competence of the models showed that the non-significant parameters of both RSM approaches (Table 2) did not improve the reached solution and, in contrast, all significant parameters were highly consistent $(\mathrm{p}<.01)$. This was also verified by the achieved high $R^{2}$ and $R_{\text {adj }}^{2}$ values, indicating the percentage of variability explained by the model. The distribution of the residuals presented in was arbitrarily around zero and no group of values or autocorrelations were observed. Additionally, the agreement between the experimental and predicted values implies an acceptable explanation of the results obtained by the independent variables used. Therefore, the models developed in Eqs. (2), (3) and (4) are completely functional and adequate to be used for prediction and process optimization.

\subsubsection{Numerical optimal conditions that maximize the extraction}

Once the models are validated, the numerical optimal conditions that maximize the extraction can be assessed. By applying a simple procedure inserting restrictions to the experimental ranges, the optimal conditions that maximize the responses criteria individually, relative or globally are achieved and presented in Table 3. The values found are discussed next:

- The optimal individual variable conditions that maximize each of the response criteria used were: for the yield $157.4 \mathrm{~min}, 20.0{ }^{\circ} \mathrm{C}$ and $0.0 \%$ of S (or $100 \%$ of water) producting $32.75 \%$ of R; for the $P h-Y_{1}$ $160.7 \mathrm{~min}, 90.0{ }^{\circ} \mathrm{C}$ and $0.0 \%$ of $\mathrm{S}$ producting $10.08 \mathrm{mg} \mathrm{GAE} / \mathrm{g} \mathrm{dw}$; and for the $P h-Y_{2} 160.7 \mathrm{~min} 90.0^{\circ} \mathrm{C}$ and $42.1 \%$ of S producting 43.30 mg GAE/g R.

- The relative optimal variable conditions for the response analysis of the $\mathrm{Ph}$ content were: for the yield $160.7 \mathrm{~min}, 90.0{ }^{\circ} \mathrm{C}$ and $15.6 \%$ of $\mathrm{S}$ producting $9.8 \mathrm{mg} \mathrm{GAE} / \mathrm{g} \mathrm{dw}\left(P h-Y_{1}\right)$ and $42.0 \mathrm{mg} \mathrm{GAE} / \mathrm{g} \mathrm{R}\left(P h-Y_{2}\right)$.

- The global optimal variable conditions for all the response criteria were $140.6 \mathrm{~min}, 90.0^{\circ} \mathrm{C}$ and $72.4 \%$ of $S$ producing $20.61 \%$ (yield), $7.7 \mathrm{mg} \mathrm{GAE} / \mathrm{g} \mathrm{dw}\left(P h-Y_{1}\right)$ and $39.7 \mathrm{mg} \mathrm{GAE} / \mathrm{g} \mathrm{R}\left(P h-Y_{2}\right)$.

In all cases, the conditions that lead to the optimal values were experimentally tested in order to ensure the accuracy of the presented results. Fig. 1, part B, shows the summarized individual 2D responses as a function of the defined variables to illustrate the most favourable conditions. The line represents the variable response pattern when the others are located at the optimal global conditions (presented in the third part of Table 3 ). The dots $(\odot)$ presented alongside the line highlight the location of the optimal value. When combining, the information produced by the three responses criteria (yield, $P h-Y_{1}$ and $P h-Y_{2}$ ), the complete behaviour of each relevant variable influencing the responses is defined in precise form regarding the $\mathrm{Ph}$ extraction from $P$. sajor-caju.

\subsection{Chemical characterization of the optimized extract}

PSC extract obtained in the optimized conditions was analyzed using HPLC-DAD-ESI/MS. $p$-Hydroxybenzoic, $p$-coumaric and cinnamic acids were identified in the extract at the following concentrations, respectively: $66 \pm 4,43.7 \pm 0.9$ and $37.5 \pm 0.3 \mu \mathrm{g} / \mathrm{g}$ extract (Table A2). The presence of these compounds was reported in many other mushrooms species (Nattoh, Musieba, Gatebe, \& Mathara, 2016). However, according to Carrasco-González, Serna-Saldívar, and Gutiérrez-Uribe (2017), mushrooms' chemical composition varies drastically with the substrate where they grow.

\subsection{Bioactive properties of the optimized extract}

\subsubsection{Antioxidant activity}

Four in vitro assays were used to evaluate the antioxidant properties of the PSC extract: DPPH scavenging activity, reducing power, $\beta$ - 
Table 4

Antioxidant, cytotoxic, antibacterial and anti-inflammatory activities of $P$. sajor-caju (mean $\pm \mathrm{SD}$ ).

\begin{tabular}{|c|c|c|c|}
\hline Antioxidant $\mathrm{EC}_{50}$ values $(\mathrm{mg} / \mathrm{ml})^{\mathrm{A}}$ & & Antimicrobial MIC values $(\mathrm{mg} / \mathrm{ml})$ & \\
\hline DPPH scavenging activity & $13.3 \pm 0.3$ & Gram negative bacteria & \\
\hline Reducing power & $2.06 \pm 0.08$ & Escherichia coli ESBL & $>20$ \\
\hline$\beta$-carotene bleaching inhibition & $8.3 \pm 0.4$ & Escherichia coli & $>20$ \\
\hline TBARS & $2.61 \pm 0.08$ & Klebsiella pneumonia & $>20$ \\
\hline Cytotoxic $\mathrm{GI}_{50}$ values $(\mu \mathrm{g} / \mathrm{ml})^{\mathrm{B}}$ & & Klebsiella pneumoniae ESBL & $>20$ \\
\hline MCF-7 (breast carcinoma) & $250 \pm 22$ & Gram positive bacteria & \\
\hline NCI-H460 (non-small cell lung carcinoma) & $246 \pm 18$ & Enterococcus faecalis & $>20$ \\
\hline HeLa (cervical carcinoma) & $308 \pm 22$ & Listeria monocytogenes & $>20$ \\
\hline HepG2 (hepatocellular carcinoma) & $>400$ & Pseudomonas aeruginosa & $>20$ \\
\hline Hepatotoxic $\mathrm{GI}_{50}$ values $(\mu \mathrm{g} / \mathrm{ml})^{\mathrm{B}}$ & & Morganela Morganii & $>20$ \\
\hline PLP2 & $>400$ & MRSA & 10 \\
\hline Anti-inflammatory $\mathrm{IC}_{50}$ value $(\mu \mathrm{g} / \mathrm{ml})^{\mathrm{C}}$ & & MSSA & 10 \\
\hline Raw 264.7 macrophages (NO inhibition) & $339 \pm 15$ & & \\
\hline
\end{tabular}

$\mathrm{EC}_{50}$ values correspond to the extract concentration achieving $50 \%$ of antioxidant activity or 0.5 of absorbance in reducing power assay. $\mathrm{GI}_{50}$ values correspond to the extract concentration achieving $50 \%$ of growth inhibition in human tumour cell lines or in liver primary culture PLP2. IC 50 value corresponds to the extract concentration responsible for $50 \%$ inhibition of NO production. A - Trolox EC 50 values: $62.98 \mu \mathrm{g} / \mathrm{ml}(\mathrm{DDPH}) ; 45.71 \mu \mathrm{g} / \mathrm{ml}$ (reducing power); $10.25 \mu \mathrm{g} / \mathrm{ml}(\beta$ carotene bleaching inhibition). B - Ellipticine GI 50 values: $1.21 \mathrm{mg} / \mathrm{ml}$ (MCF-7); $1.03 \mathrm{mg} / \mathrm{ml}$ (NCI-H460); $0.91 \mathrm{mg} / \mathrm{ml}$ (HeLa); $1.10 \mathrm{mg} / \mathrm{ml}$ (HepG2) and 2.29 mg/ml (PLP2). C - Dexamethasone IC $_{50}$ value $=16 \pm 2 \mu \mathrm{g} / \mathrm{ml}$ (Raw 264.7). MIC values correspond to the minimal sample concentration that inhibited the bacterial growth.

carotene bleaching and lipid peroxidation (TBARS) inhibition; the results are shown in Table 4. The lowest $\mathrm{EC}_{50}$ values (highest antioxidant activity) were obtained in the reducing power and TBARS assays. According to Ferreira et al. (2009), the secondary metabolites produced by mushrooms, including phenolic acids, have a strong ability as free radical scavengers. The bioactivity of these compounds is correlated to their chemical structure consisting of an aromatic ring with hydroxyl substituents (Reis, Martins, Barros, \& Ferreira, 2012). Therefore, PSC extract can help in the control of oxidative damage caused by free radicals.

\subsubsection{Cytotoxicity in tumour and non-tumour cells}

The results of the cytotoxicity of the PSC extract on human tumour cell lines and on non-tumour cells are shown in Table 4. The extract was able to inhibit the cell growth of NCI-H460 (non-small cell lung carcinoma), MCF-7 (breast carcinoma) and HeLa (cervical carcinoma), but did not have effects on HepG2 cell line (hepatocellular carcinoma). Furthermore, the extract did not reveal toxicity for non-tumour cells (primary PLP2), up to the maximal concentration tested $(400 \mu \mathrm{g} / \mathrm{ml})$. Some studies have also demonstrated that PSC methanolic extract had effects on U937 (Panthong, Boonsathorn, \& Chuchawankul, 2016) and sarcoma 180 (Assis et al., 2013).

\subsubsection{Antibacterial activity}

Mushrooms have been reported to have higher activity against Gram-positive bacteria (Reis, Martins, Vasconcelos, Morales, \& Ferreira, 2017). Our study confirmed this information, as the extract was only active against MRSA and MSSA with MIC values of $10 \mathrm{mg} / \mathrm{ml}$ (Table 4). Nonetheless, Ahmad et al. (2012) reported antimicrobial activity of PSC ethanolic extracts against Pseudomonas aeruginosa, Bacillus subtilis, B. atrophaeus, Staphylococcus aureus and Klebsiella pneumoniae, while Gogavekar et al. (2014) described the activity of methanolic extracts against E. coli, Salmonella typhimurium, B. cereus, S. aureus and Micrococcus luteus. However, it should be highlighted that the tested bacteria are collection microorganisms and not clinical isolates, as the ones used in the present study.

\subsubsection{Anti-inflammatory activity}

PSC extract was able to reduce NO production in murine RAW 264.7 macrophage cells (Table 4). Similar results were observed for other Pleurotus species (Carrasco-González et al., 2017).

Recently, the interaction mechanism of several phenolic acid derivatives (anthranilic acid derivatives) with COX-2, a known anti- inflammatory target, was elucidated (Orlando \& Malkowski, 2016). Hypothesizing that the anti-inflammatory activity observed could be related to COX-2 inhibition, we perform in silico docking studies of the three major phenolic acids, found in P. sajor-caju, against COX-2. An initial docking study was performed, using the co-crystallized mefenamic acid against the selected PDB structure (PDB entry: 5KI5). A near perfect superimposition between the predicted and the experimental mefenamic acid structure was observed (Fig. 2a), demonstrating that the docking methodology used was adequate for this study. We subsequently performed docking simulations using the three major phenolic acids and a possible COX-2 mechanism of inhibition is presented (Fig. 2b-c). The predicted interaction between cinnamic acid and COX-2 is mainly stabilized by two hydrogen bonds (H-bonds) between the carboxyl group of cinnamic acid and two COX-2 residues (Tyr385 and Ser530), while the phenyl ring occupies the same interaction space as mefenamic acid (Fig. 2b). p-Coumaric acid is also predicted to form an H-bond between its hydroxyl group and Tyr385 while also forming a second H-bond with Tyr355. Finally, $p$-hydroxybenzoic acid is predicted to form $\mathrm{H}$-bonds with Tyr385 and Ser530, while also forming a third H-bond with the peptide bond between Val523 and Glu524. Although the predicted interaction conformations need to be experimentally validated, this docking analysis demonstrates that COX-2 is a plausible target for the phenolic acids discovered in $P$. sajor-caju, and that the anti-inflammatory activity observed can possibly be a result of a synergistic effect between different phenolic acids or phenolic acid derivatives.

\section{Conclusions}

The effects of three independent variables ( $t, T$ and $S$ ) was optimized for maximizing yield and $\mathrm{Ph}$ compounds extraction from $P$. sajor-caju using HAE. RSM methodology was applied using a CCCD of three factors with five-levels and second-order polynomial models, which were successfully designed and experimentally verified, showing that the studied variables have significant effects on the responses. In all cases, the used RSM models were statistically significant and their application allowed the optimization, resulting in enriched extracts in $\mathrm{Ph}$ compounds. Afterwards, the extracts were analyzed in terms of its chemical composition an in terms of its bioactive properties. The results produced of the enriched extracts in phenolic compounds shows a promising and broad range of bioactivities, with potential application in different industrial fields (food, pharmaceutical and cosmetic sectors). 


\section{Acknowledgements}

The authors are grateful to the Foundation for Science and Technology (FCT, Portugal) and FEDER under Program PT2020 for financial support to CIMO (UID/AGR/00690/2013) and for L. Barros and R. Calhelha contracts. T.C. Finimundy thanks CAPES Foundation, Ministry of Education of Brazil (CAPES fellow, process number 88881.134581/2016-01). To Xunta de Galicia for financial support for the post-doctoral researcher of M.A. Prieto.

\section{Appendix A. Supplementary data}

Supplementary data associated with this article can be found, in the online version, at http://dx.doi.org/10.1016/j.foodchem.2017.10.088.

\section{References}

Ademola, I. O., \& Odeniran, P. O. (2017). Novel trypanocide from an extract of Pleurotus sajor-caju against Trypanosoma congolense. Pharmaceutical Biology, 55(1), 132-138.

Ahmad, N., Mahmood, F., Khalil, S. A., Zamir, R., Fazal, H., \& Abbasi, B. H. (2012). Antioxidant activity via DPPH, gram-positive and gram-negative antimicrobial potential in edible mushrooms. Toxicology and Industrial Health, 30(9), 826-834.

Albuquerque, B. R., Prieto, M. A., Barreiro, M. F., Rodrigues, A., Curran, T. P., \& Barros, L. (2017). Catechin-based extract optimization obtained from Arbutus unedo L. fruits using maceration/microwave/ultrasound extraction techniques. Industrial Crops \& Products, 95, 11.

Alves, M. J., Ferreira, I. C. F. R., Dias, J., Teixeira, V., Martins, A., \& Pintado, M. (2013). A review on antifungal activity of mushroom (Basidiomycetes) extracts and isolated compounds. Current Topics in Medicinal Chemistry, 13(21), 2648-2659.

AOAC, (2016). Official Methods of Analysis. In A. Arlington (Ed.), Association of Official Analytical Chemists, 16th ed.).

Assis, I. S., Chaves, M. B., Silveira, M. L., Gern, R. M., Wisbeck, E., Junior, A. F., et al. (2013). Production of bioactive compounds with antitumor activity against sarcoma 180 by Pleurotus sajor-caju. Journal of Medicinal Food, 16(11), 1004-1012.

Barros, L., Duenas, M., Ferreira, I. C. F. R., Baptista, P., \& Santos-Buelga, C. (2009). Phenolic acids determination by HPLC-DAD-ESI/MS in sixteen different Portuguese wild mushrooms species. Food and Chemical Toxicology, 47(6), 1076-1079.

Carrasco-González, J. A., Serna-Saldívar, S. O., \& Gutiérrez-Uribe, J. A. (2017). Nutritional composition and nutraceutical properties of the Pleurotus fruiting bodies: Potential use as food ingredient. Journal of Food Composition and Analysis, 58, 69-81.

Chang, S. T., \& Wasser, S. P. (2012). The role of culinary-medicinal mushrooms on human welfare with a pyramid model for human health. International Journal of Medicinal Mushrooms, 14(2), 95-134.

CLSI, (2008). Clinical Lab Standards Institute. Clinical Lab Standards Institute.

Delano, W. L. (2002). The PyMOL Molecular Graphics System. In).

Duru, M. E., \& Cayan, G. T. (2015). Biologically active terpenoids from mushroom origin: A review. Records of Natural Products, 9(4), 456-483.

EUCAST, (2013). European Committee on Antimicrobial Susceptibility Testing. European Committee on Antimicrobial Susceptibility Testing.

Ferreira, I. C. F. R., Barros, L., \& Abreu, R. M. (2009). Antioxidants in wild mushrooms. Current Medicinal Chemistry, 16(12), 1543-1560.

Ferreira, I. C. F. R., Heleno, S. A., Reis, F. S., Stojkovic, D., Queiroz, M. J. R. P., Vasconcelos, M. H., et al. (2015). Chemical features of Ganoderma polysaccharides with antioxidant, antitumor and antimicrobial activities. Phytochemistry, 114, 38-55.

Gogavekar, S. S., Rokade, S. A., Ranveer, R. C., Ghosh, J. S., Kalyani, D. C., \& Sahoo, A. K. (2014). Important nutritional constituents, flavour components, antioxidant and antibacterial properties of Pleurotus sajor-caju. Journal of Food Science and Technology, 51(8), 1483-1491.

Goyal, R., Grewal, R. B., \& Goyal, R. K. (2006). Nutritional attributes of Agaricus Bisporus and Pleurotus sajor caju mushrooms. Nutrition and Health, 18(2), 179-184.

Gupta, A., Sharma, S., Saha, S., \& Walia, S. (2013). Yield and nutritional content of Pleurotus sajor caju on wheat straw supplemented with raw and detoxified mahua cake. Food Chemistry, 141(4), 4231-4239.

Han, N. S., Ahmad, W. A. N. W., \& Ishak, W. R. W. (2016). Quality characteristics of Pleurotus sajor-caju powder: Study on nutritional compositions, functional properties and storage stability. Sains Malaysiana, 45(11), 1617-1623.

Heleno, S. A., Barros, L., Martins, A., Morales, P., Fernandez-Ruiz, V., Glamoclija, J., et al. (2015). Nutritional value, bioactive compounds, antimicrobial activity and bioaccessibility studies with wild edible mushrooms. LWT-Food Science and Technology, 63(2), 799-806.

Heleno, S. A., Prieto, M. A., Barros, L., Rodrigues, A., Barreiro, M. F., \& Ferreira, I. C. F. R. (2016). Optimization of microwave-assisted extraction of ergosterol from Agaricus bisporus L. by-products using response surface methodology. Food and Bioproducts Processing, 100, 25-35.

Kanagasabapathy, G., Kuppusamy, U. R., Abd Malek, S. N., Abdulla, M. A., Chua, K.-H., \& Sabaratnam, V. (2012). Glucan-rich polysaccharides from Pleurotus sajor-caju (Fr.) Singer prevents glucose intolerance, insulin resistance and inflammation in C57BL/6J mice fed a high-fat diet. BMC Complementary and Alternative Medicine, 12 261-261.

Kayode, R. M. O, Olakulehin, T. F., Adedeji, B. S., Ahmed, O., Aliyu, T. H., \& Badmos, A. H. A. (2015). Evaluation of amino acid and fatty acid profiles of commercially cultivated oyster mushroom (Pleurotus sajor-caju) grown on gmelina wood waste. Nigerian Food Journal, 33(1), 18-21.

Khan, M. A., \& Tania, M. (2012). Nutritional and medicinal importance of Pleurotus mushrooms: An overview. Food Reviews International, 28(3), 313-329.

Milić, P. S., Rajković, K. M., Stamenković, O. S., \& Veljković, V. B. (2013). Kinetic modeling and optimization of maceration and ultrasound-extraction of resinoid from the aerial parts of white lady's bedstraw (Galium mollugo L.). Ultrasonics Sonochemistry, 20(1), 525-534.

Morris, G. M., Huey, R., \& Olson, A. J. (2008). Using AutoDock for ligand-receptor docking. Current Protocols in Bioinformatics, Chapter 8, Unit 814.

Nattoh, G., Musieba, F., Gatebe, E., \& Mathara, J. (2016). Towards profiling differential distribution of bioactive molecules across four phenologies in Pleurotus djamor R22. Asian Pacific Journal of Tropical Disease, 6(6), 472-480.

Obodai, M., Ferreira, I. C. F. R., Fernandes, A., Barros, L., Mensah, D. L., Dzomeku, M., et al. (2014). Evaluation of the chemical and antioxidant properties of wild and cultivated mushrooms of Ghana. Molecules, 19(12), 19532-19548.

Orlando, B. J., \& Malkowski, M. G. (2016). Substrate-selective inhibition of cyclooxygeanse-2 by fenamic acid derivatives is dependent on peroxide tone. Journal of Biological Chemistry, 291(29), 15069-15081.

Panthong, S., Boonsathorn, N., \& Chuchawankul, S. (2016). Antioxidant activity, antiproliferative activity, and amino acid profiles of ethanolic extracts of edible mush rooms. Genetics and Molecular Research, 15(4).

Prieto, M. A., Curran, T. P., Gowen, A., \& Vázquez, J. A. (2015). An efficient methodology for quantification of synergy and antagonism in single electron transfer antioxidant assays. Food Research International, 67, 284-298.

Prieto, M. A., Murado, M. A., \& Vázquez, J. A. (2014). Quantification, characterization and description of synergy and antagonism in the antioxidant response. Food Research International, 60, 218-229.

Reis, F. S., Martins, A., Barros, L., \& Ferreira, I. C. F. R. (2012). Antioxidant properties and phenolic profile of the most widely appreciated cultivated mushrooms: A comparative study between in vivo and in vitro samples. Food and Chemical Toxicology, 50(5), 1201-1207.

Reis, F. S., Martins, A., Vasconcelos, M. H., Morales, P., \& Ferreira, I. C. F. R. (2017). Functional foods based on extracts or compounds derived from mushrooms. Trends in Food Science \& Technology, 66, 48-62.

Svobodova, B., Barros, L., Sopik, T., Calhelha, R. C., Heleno, S., Alves, M. J., et al. (2017). Non-edible parts of Solanum stramoniifolium Jacq. - A new potent source of bioactive extracts rich in phenolic compounds for functional foods. Food \& Function, 8, 2013-2021.

Taofiq, O., Heleno, S. A., Calhelha, R. C., Alves, M. J., Barros, L., Barreiro, M. F., et al. (2016). Development of mushroom-based cosmeceutical formulations with anti-inflammatory, anti-tyrosinase, antioxidant, and antibacterial properties. Molecules, 21(10), 1372.

Teplyakova, T. V., \& Kosogova, T. A. (2016). Antiviral effect of Agaricomycetes mushrooms (review). International Journal of Medicinal Mushrooms, 18(5), 375-386.

Trott, O., \& Olson, A. J. (2010). AutoDock Vina: Improving the speed and accuracy of docking with a new scoring function, efficient optimization, and multithreading. Journal of Computational Chemistry, 31(2), 455-461.

Vongsak, B., Sithisarn, P., Mangmool, S., Thongpraditchote, S., Wongkrajang, Y., \& Gritsanapan, W. (2013). Maximizing total phenolics, total flavonoids contents and antioxidant activity of Moringa oleifera leaf extract by the appropriate extraction method. Industrial Crops and Products, 44, 566-571.

Yang, J.-H., Lin, H.-C., \& Mau, J.-L. (2002). Antioxidant properties of several commercial mushrooms. Food Chemistry, 77(2), 229-235. 